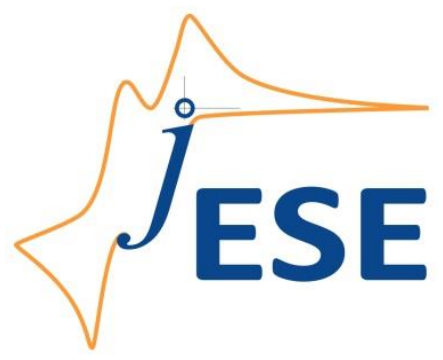

Open Access: ISSN 1847-9286

www.jESE-online.org

Original scientific paper

\title{
Electroanalytical methods in characterization of sulfur species in aqueous environment
}

\author{
Irena Ciglenečki ${ }^{凶}$, Marija Marguš, Elvira Bura-Nakić and Ivana Milanović \\ Division for Marine and Environmental Research, Ruđer Bošković Institute, Bijenička 54, \\ 10000 Zagreb, Croatia \\ ${ }^{\triangle}$ Corresponding author: E-mail: irena@irb.hr; Tel: $0038514561105 ;$ Fax: 0038514680242
}

Received: April 10, 2014; Revised: June 13, 2014; Published: December 6, 2014

\begin{abstract}
Electroanalytical (voltammetric, polarographic, chronoamperometric) methods on an $\mathrm{Hg}$ electrode were applied for studying of different sulfur compounds in model and natural water systems (anoxic lakes, waste water, rain precipitation, sea-aerosols). In all investigated samples typical HgS reduction voltammetric peak, characteristic for many different reduced sulfur species (RSS: sulfide, elemental sulfur, polysulfide, labile metal sulfide and organosulfur species) was recorded at about $0.6 \mathrm{Vvs} . \mathrm{Ag} / \mathrm{AgCl}$ reference electrode. In addition, in anoxic waters which are enriched with sulfide and iron species, voltammetric peaks characteristic for the presence of free $\mathrm{Fe}(I I)$ and FeS nanoparticles (NPs) were recorded at $-1.4 \mathrm{~V}$ and around $-0.45 \mathrm{~V}$, respectively. Depending on the used electroanalytical method and experimental conditions (varying deposition potential, varying time of oxidative and/or reductive accumulation, sample pretreatment i.e. acidification followed by purging) it is possible to distinguish between different sulfur species. This work clearly shows a large potential of the electrochemistry as a powerful analytical technique for screening water quality regarding presence of different reduced sulfur species and their speciation between dissolved and colloidal/nanoparticle phases.
\end{abstract}

\section{Keywords}

Voltammetry; chronoamperometry; speciation; reduced sulfur species; metal sulfide nanoparticles; Hg electrode; anoxic water samples

Electrochemical measurements are along with ICP-MS, the most used but challenging approaches in essential elements analysis and speciation in complex natural samples. There is a wide range of electroanalytical techniques for qualitative and quantitative determination of essential and potentially toxic elements in natural waters [1,2]. Some examples include: potentiometry, polarography, voltammetry, chronopotentiometry, chronoamperometry, etc. These electrochemical methods, especially voltammetry, have appropriate features to be used as monitoring methods (early warning tools) for assessment of water quality in aqueous systems in general and will be key 
methods for trace pollutant analyses (sulfur species [3-17], organic compounds [18-20], trace metals [2-4, 8, 21-26], engineered and natural nanoparticles [27-34]).

Working electrodes, so called voltammetric sensors, have many embodiments that make them specific for detection of above listed natural and anthropogenically introduced compounds in natural environment, enabling their quantitative determination. Electrochemical techniques offer increasing degree of accuracy, decreasing detection limits, simplicity, prompt response, ect. It involves dramatically lower costs than other techniques to reach same sensibility and with automated, portable instrumentation is suitable for fieldwork. In addition, many substances that are analyzed by other techniques use electrochemical detectors.

Voltammetry is the only technique allowing speciation and determination of the truly dissolved metal species without many sample handling [2,21-26]. Speciation of a metal affects its biogeochemical cycling processes and its biological impacts. Thus, electrochemical measurements in natural waters are essential in order to obtain more complete speciation information and to fully understand the geochemical cycling and bioavailability (toxicity) of trace metals.

EU water quality guidelines are searching for new innovative methods for water quality monitoring, and electrochemistry in comparison with Inductively Coupled Plasma Mass Spectrometry (ICP-MS) and/or Inductively coupled plasma/optical emission spectrometry (ICP-OES) and diffusive gradients in thin-films (DGT) approach was found as preferable choice. Besides, new investigations showed that voltammetry has a potential to be used in determination of metal NPs, metal sulfide (MS) NPs and aquatic colloids in natural waters [27-32]. Growing evidence implies that MS NPs of natural and anthropogenic origin exist in aquatic environments. These NPs could play important role as mediators of the trace metal nutrition and toxicity. Using different electrochemical methods it is possible to measure a variety of soluble and particulate sulfur compounds [3-17,32].

In this work voltammetric, polarographic and chronoamperometric measurements on a $\mathrm{Hg}$ electrode were used for characterization and speciation of dissolved and particulate sulfur species, including thiols, $\mathrm{HS}^{-}, \mathrm{S}^{0}, \mathrm{MS} N \mathrm{NP}(\mathrm{FeS}, \mathrm{PbS}), \mathrm{S}_{\mathrm{x}}{ }^{2-}$ in different contrasting aqueous natural samples such as oxic/anoxic systems, rain precipitation and aerosols.

\section{Experimental}

\section{Materials}

All chemicals used were reagent grade and were not further purified. Stock solutions of sulfide, polysulfide, suspensions containing NPs of FeS and PbS were prepared as previously described [6, 7, 10-14, 32]. All measurements were performed in $\mathrm{NaCl}$ (Chemica, Croatia) electrolyte solutions with ionic strengths ranging from 0.11 to $0.55 \mathrm{M} \mathrm{NaCl}$. In some experiments the $\mathrm{NaCl}$ electrolyte was buffered with $0.03 \mathrm{M} \mathrm{NaHCO}_{3}$ (Chemica, Croatia).

\section{Instrumentation}

Electrochemical measurements were performed with a BAS-100-A chemical analyser, $\mu$-Autolab Electrochemical Instruments (Eco Chemie) and PGSTAT $128 \mathrm{~N}$ (Metrohm, Switzerland) connected to pencil like HMDE and 663 VA Stand Metrohm Electrode (Metrohm, Switzerland) as a working electrodes, respectively. The reference electrode was an $\mathrm{Ag} / \mathrm{AgCl}$ (3 M KCl) electrode connected to the solution via an electrolyte bridge, and a platinum electrode served as an auxiliary electrode.

Reduced sulfur species (RSS) were determined by linear sweep and cyclic voltammetry (LSV, CV) $[6,7,13]$ and by polarographic measurements [3] in fresh nonfiltered samples. In the case of CV and LSV the accumulation ( $t_{a}=0-120 \mathrm{~s}$ ) of RSS on the $\mathrm{Hg}$ electrode surface with stirring was 
performed at the deposition potential of $E=-0.20 \mathrm{~V}(\mathrm{vs} . \mathrm{Ag} / \mathrm{AgCl})$. After accumulation the potential was shifted in the negative direction (to $E=-1.70 \mathrm{~V} \mathrm{vs}$. $\mathrm{Ag} / \mathrm{AgCl}$ ) with a scan rate of $100 \mathrm{mV} / \mathrm{s}$ and $\mathrm{HgS}$ reduction peak at around $-0.6 \mathrm{~V}$, characteristic of many RSS were recorded $[6,7,13]$. In the same cycle reduction peaks characteristics for the presence of metal sulfide layers and NPs from the bulk of the solution were recorded at potential more negative than $-0.6 \mathrm{~V}[10,11,17]$. Next, the solution was acidified with $30 \mu \mathrm{L}$ of concentrated $\mathrm{HCl}$ (Chemica, Croatia) to $\mathrm{pH} \sim 2$ and purged for 5 min. After restoring the original $\mathrm{pH}$ with $\mathrm{NaOH}$ (Chemica, Croatia) the accumulation and scan steps were repeated. The result of the first measurement, prior to acidification, is assigned as total reduced sulfur species, $\mathrm{RSS}_{\mathrm{T}}=\mathrm{H}_{2} \mathrm{~S} / \mathrm{HS}^{-}+\mathrm{S}^{0}$ and the result of the second measurement is assigned to elemental sulfur, $S^{0}$ as model representative for non-volatile reduced sulfur species, $\operatorname{RSS}_{\mathrm{NV}}[6,7,13]$.

For detection of $S^{0}$ and $S^{2-}$ presence in polysulfide (Alfa Aesar, USA) containing solutions sampled DC polarography (SDC) or voltammetry at the $\mathrm{Hg}$ electrode was performed with step potential of $0.0051 \mathrm{~V}$, starting from $-0.4 \mathrm{~V}(\mathrm{vs}$. $\mathrm{Ag} / \mathrm{AgCl})$ and shifting to more negative values.

In chronoamperometry the detection potential at which current was measured as a function of time (I-t curves) was selected depending on the potential at which reduction of the NPs from the bulk of the solution is proceeding $[11,17,32]$. In the case of PbS the used potential was $-1.5 \mathrm{~V}$. The scan lasted for $30 \mathrm{~s}$ and the sampling time was $0.1 \mathrm{~s}$. The suspension of PbS NPs was prepared by mixing the equimolar concentrations of $\mathrm{Pb}^{2+}$ and $\mathrm{HS}^{-}$directly in the electrochemical cell [11]. During the ageing process the suspension was not stirred and recorded changes in the NPs sizes were only due to aggregation caused by Brownian motion.

\section{Results and discusion}

Typical voltammetric signal which can be found in an anoxic sulfide rich environment is presented in Fig. 1. The obtained peak, usually in our papers designated as C2, represents the wellknown dissolution/reduction of HgS layer on the $\mathrm{Hg}$ electrode surface [5-7,9-17]:
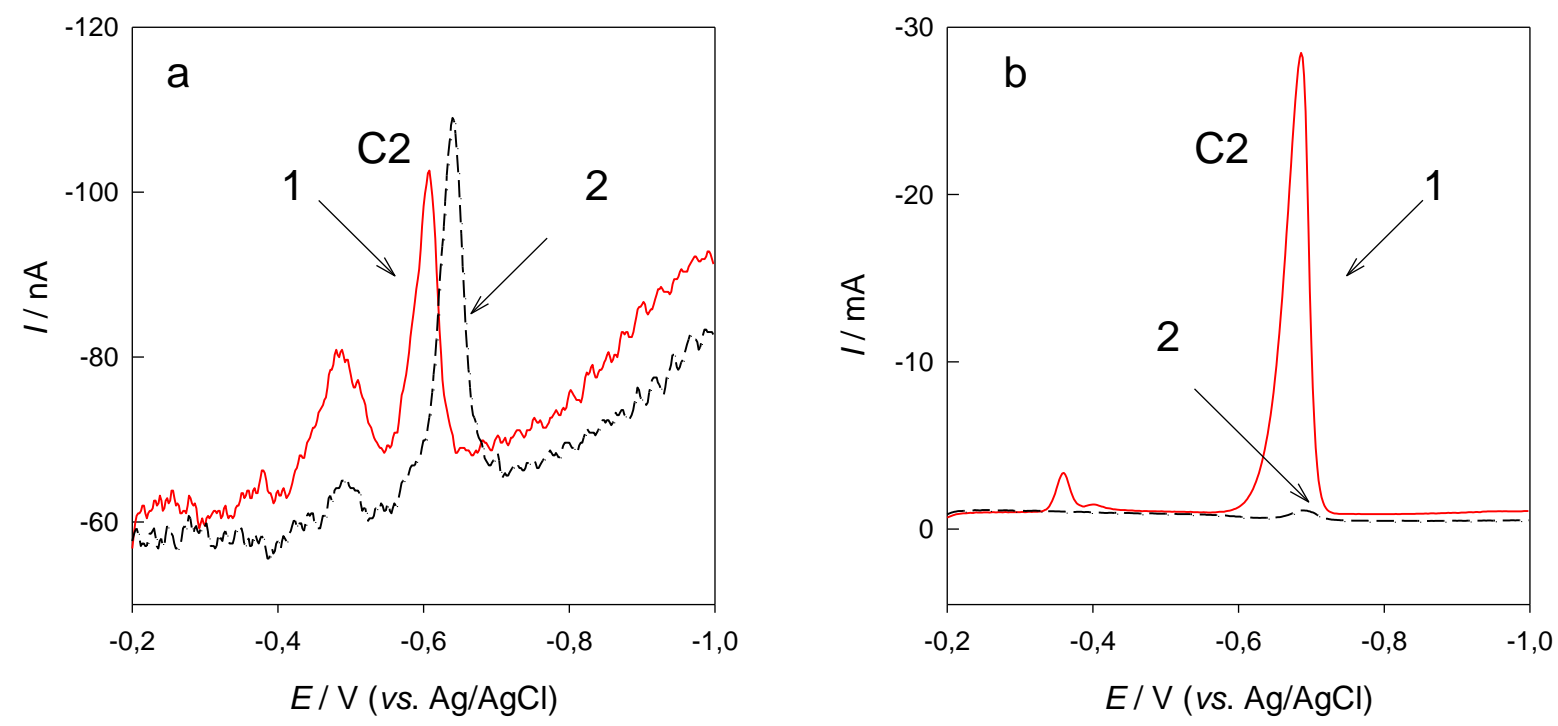

Figure 1. LSV obtained from Rogoznica Lake water in the oxic (a) and anoxic bottom water layer (b), before 1) and 2) after acidification and purging with $\mathrm{N}_{2} ;\left(\mathrm{E}=-0.2 \mathrm{~V}, \mathrm{t}_{a}=120 \mathrm{~s}\right)$. The $C 2$ peak increases with either sulfide or with $S^{0}$ addition and corresponds to $6.5 \mathrm{nM} R \mathrm{RSS}_{N V}$ in a) and to $\mathrm{mM}$ RSSV in $b$. The shift of this peak to a more negative potential after the acid-purge-base treatment is due to a final $\mathrm{pH}$ which is higher than the original $\mathrm{pH}$. Carbonate buffering in the sample is destroyed by acidification, so it is difficult to return the sample exactly to the original $\mathrm{pH}$. 


$$
\mathrm{HgS}+\mathrm{H}^{+}+2 \mathrm{e}^{-} \rightarrow \mathrm{HS}^{-}+\mathrm{Hg}^{0}
$$

This peak usually is taken as a measure for "free" and labile sulfur species content $\left(\mathrm{H}_{2} \mathrm{~S} / \mathrm{HS}^{-} / \mathrm{S}^{2-}, \mathrm{S}^{0}\right.$, $\mathrm{S}_{\mathrm{n}} \mathrm{S}^{2-}$, thiols, labile metal sulfide complexes and nanoparticles). In oxic water layers, in addition to $\mathrm{C} 2$, the peak at more positive potentials than $-0.5 \mathrm{~V}$ can be frequently revealed. This peak usually corresponds to the presence of different organosulfur species (DMS, 3-mercaptopropionat, thiocompounds) which at used experimental conditions oxidize the $\mathrm{Hg}$ electrode but do not deposit HgS layer on its surface, therefore their peak appears more positively than C2 [9].

In cases when sample solution contains sulfide and metal ions $\left(\mathrm{M}^{2+}\right)$ which are present in an excess, depending on the electrochemical conditions (deposition potential, accumulation time) $[15,17]$, the peak marked as C3 (Figure 2) appears. This peak corresponds to formation of metal sulfide (MS) deposit (layers), in the given case $\mathrm{PbS}$, due to electrochemical exchange reaction between $\mathrm{Hg}^{2+}$ from a $\mathrm{HgS}$ layer and the free $\mathrm{M}^{2+}\left(\mathrm{Pb}^{2+}\right)$ ion from the solution $[15,17]$ :

$$
\mathrm{HgS}_{\text {layer }}+\mathrm{M}^{2+}+2 \mathrm{e}^{-} \leftrightarrow \mathrm{MS}_{\text {layer }}+\mathrm{Hg}^{0}
$$

C3 might be easily misrepresented for the dissolved organosulfur species represented by C2 peak in Figure 1.

The MS layer stays on the $\mathrm{Hg}$ surface without desorption up to potentials that are more negative than $\mathrm{C} 2$ peak (usually up to $-1.6 \mathrm{~V}$ and more negative potentials) $[14,17,32]$. Reduction of the MS (PbS) layers formed at C3 peak potential usually occurs at potentials of the peak C5 (Figure 2, reaction 3). The potentials of both electrode reactions, and the formation and reduction of the MS layer, are shown to be directly controlled by the MS solubility products $[15,17]$.

$$
\mathrm{PbS}_{\text {layer }}+2 \mathrm{e}^{-}+\mathrm{H}^{+} \rightarrow \mathrm{Pb}^{0}+\mathrm{HS}^{-}
$$

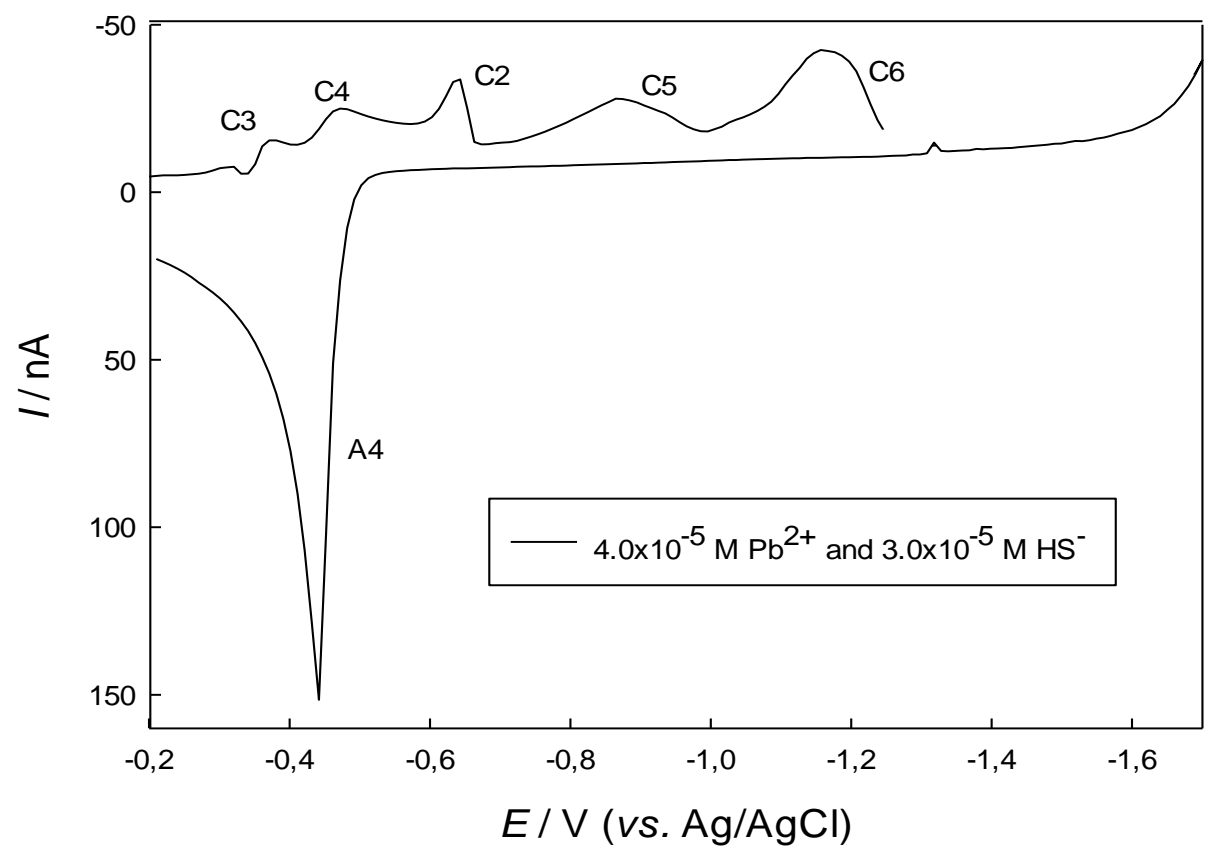

Figure 2. $\mathrm{CV}$ of solution containing $4 \times 10^{-5} \mathrm{M} \mathrm{Pb}^{2+}$ and $3 \times 10^{-5} \mathrm{M} \mathrm{HS}^{-}$in $0.55 \mathrm{M} \mathrm{NaCl} / 0.03 \mathrm{M}$ $\mathrm{NaHCO}_{3}$ electrolyte ( $\left.\mathrm{E}=-0.2 \mathrm{~V} ; t_{a}=60 \mathrm{~s} ; \mathrm{v}=100 \mathrm{mV} / \mathrm{s}\right)$.

C4/A4 peaks in the Figure 2, correspond to reduction/oxidation of the free metal on the $\mathrm{Hg}$, i.e. to the reduction of $\mathrm{Pb}^{2+}$ to $\mathrm{Pb}^{0}$, while $\mathrm{C} 6$ in accordance with our previous work was ascribed to reduction of $\mathrm{PbS}$ nanoparticles (NPS) from the bulk of the studied solutions $[10,11,17]$. These particles usually do not form MS layers. In the case of studied $\mathrm{CdS}, \mathrm{PbS}, \mathrm{Ag}_{2} \mathrm{~S}, \mathrm{Cu}_{2} \mathrm{~S}, \mathrm{HgS}$ 
suspensions, depending on the solution conditions (concentration and ratio between metal and sulfide species, ionic strength, $\mathrm{pH}$ ) larger NPs will form and result in the appearance of the peaks similar to recorded C6 reduction peak. Direct reduction of the formed NPs, which is placed more negative than reduction process of the relevant MS layers [17] and/or reduction processes which occur on the NPs surface upon collision with the $\mathrm{Hg}$ electrode, and the potential where this process is occurring on the $\mathrm{Hg}$ surface is successfully used as a background for further NPs characterization by chronoamperometric measurements [32], as shown here later.

In samples of anoxic seawater lake Rogoznica Lake (Croatia), shown in Figure 1, the peak at -0.5 $\mathrm{V}$ corresponds to the presence of organosulfur species $\left(\mathrm{RSS}_{\mathrm{NV}}\right.$ ) which do not deposit $\mathrm{HgS}$, and peak at $-0.6 \mathrm{~V}$ corresponds to presence of $\mathrm{RSS}_{\text {total }}$ (all RSS that deposit HgS). The major difference between oxic and anoxic Rogoznica lake water layers is in the existence of volatile sulfide species $\left(\mathrm{RSS}_{\mathrm{V}}\right.$ ) which are present in $\mathrm{mM}$ concentration in anoxic part mainly in the form of sulfide (HS') and $\mathrm{RSS}_{\mathrm{NV}}$ which presence is determined to be around $10 \mathrm{nM}$ in oxic and 1-10 $\mu \mathrm{M}$ in anoxic water layers. The RSSv can be removed by acidification and purging while nonvolatile species during acidification and purging procedure will remain in the sample and contribute to the C2 peak (Figure 1b) $[9,12,13,16]$.

With use of polarographic measurements on the $\mathrm{Hg}$ electrode it is possible to distinguish further between detected RSS on the polysulfide $\left(\mathrm{S}_{\mathrm{x}}{ }^{2-}\right)$, elemental $\mathrm{S}\left(\mathrm{S}^{0}\right)$ and/or $\mathrm{HS}^{-}$species without any pretreatment of the samples [3] (Figure 3).
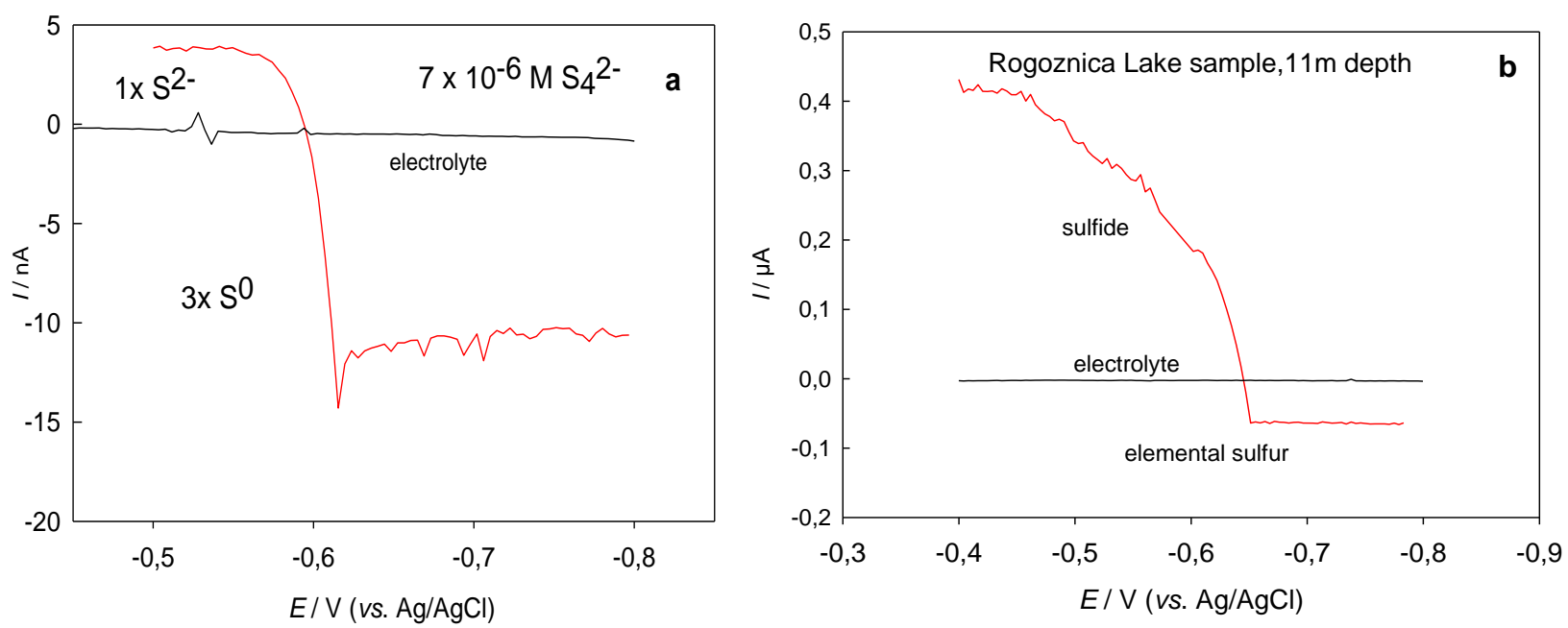

Figure 3. SDC polarographic curves recorded in: a) $0.55 \mathrm{M} \mathrm{NaCl}$ solution containing $7 \times 10^{-6} \mathrm{M} \mathrm{S}_{4}{ }^{2-}$ and b) anoxic sample od Rogoznica lake taken at $11 \mathrm{~m}$ depth. The voltammograms were recorded between -0.4 and $-0.8 \mathrm{~V}$ vs. $\mathrm{Ag} / \mathrm{AgCl}$ with potential steps of $1 \mathrm{mV}$.

The voltammograms measured in the tetrasulfide containing solution (Figure 3a) were characterized by the anodic and cathodic currents in the potential range from $-0.5 \mathrm{~V}$ to $-0.8 \mathrm{~V}$, respecttively. The cathodic current is assigned to a reduction process given by the equation (4) $[3,33,34]$, and it is a measure for the presence of $S^{0}$ in the polysulfide molecule:

$$
\mathrm{S}_{n}^{2-}+2(n-1) \mathrm{e}^{-}+n \mathrm{H}_{2} \mathrm{O} \rightarrow n \mathrm{HS}^{-}+n \mathrm{OH}^{-}
$$

Anodic current recorded at potentials more positive than $-0.6 \mathrm{~V}$ is assigned to the well-known oxidation of the $\mathrm{Hg}$ by $\mathrm{HS}^{-}$according to equation (5) [3-17,33], and it can be taken as a measure for the $S^{2-}$ presence in the molecule of polysulfide:

$\mathrm{HS}^{-}+\mathrm{Hg} \rightarrow \mathrm{HgS}+2 \mathrm{e}^{-}+\mathrm{H}^{+}$ 
Ratio between cathodic and anodic currents in the studied case of tetrasulfide solution was roughly 3:1 indicating $3 \mathrm{~S}^{0}$ and $1 \mathrm{~S}^{2-}$ in the molecule of $\mathrm{S}_{4}{ }^{2-}$. In Rogoznica Lake sample this ratio was much lower (1:6.5), pointing to a high excess of the free sulfide in the sample. Common ratio between sulfide and elemental sulfur in the anoxic Rogoznica Lake samples is 10-15 to 1 in favour of sulfide $[6,13]$.

Similar voltammetric curves to Rogoznica Lake samples with revealed C2 - RSS $\mathrm{NV}_{\mathrm{N}}$ peak can be found in rain precipitation and aerosols. Usually in these samples $\mathrm{RSS}_{\mathrm{NV}}$ are detected in much lower concentration range from 1-10 nM, while industrial waste samples could contain total RSS from $10 \mu \mathrm{M}$ up to $\mathrm{mM}$ concentration.

In sulfide and iron rich natural samples such is anoxic water column of freshwater Pavin Lake in France, voltammetric curves similar to curves obtained in MS suspensions could be recorded (Figure 4) $[12,16]$. Besides C2 peak in such samples other relevant peaks can be seen:

1) $\mathrm{C} 3 / \mathrm{A} 3$ peak couple can be attributed to transformation reaction of FeS to the $\mathrm{HgS}[14,16,35]$ :

$$
\mathrm{FeS}_{\text {layer }}+\mathrm{Hg}^{0} \rightarrow \mathrm{HgS}_{\text {layer }}+\mathrm{Fe}^{2+}+2 \mathrm{e}^{-}
$$

and can be taken as an indication and rough measure for nanoparticulate FeS $[15,16]$.

2) $\mathrm{C} 4$ is the well-known reduction peak of Fe(II) aqua ion, which is irreversibly reduced on the $\mathrm{Hg}$ near $-1.4 \mathrm{~V}[4,8,14,16,25]$ :

$$
\mathrm{Fe}^{2+}+2 \mathrm{e}^{-} \rightarrow \mathrm{Fe}^{0}
$$

3) The C1/A11 peaks arises from the reduction of $\mathrm{Fe}^{2+}$ or its labile complexes on the $\mathrm{Hg}$ electrode surface modified by a FeS layer [14,16,35 and references therein]. $\mathrm{Fe}^{0}$ deposited at the C1 would be oxidized in reverse scan at the A11 peak.
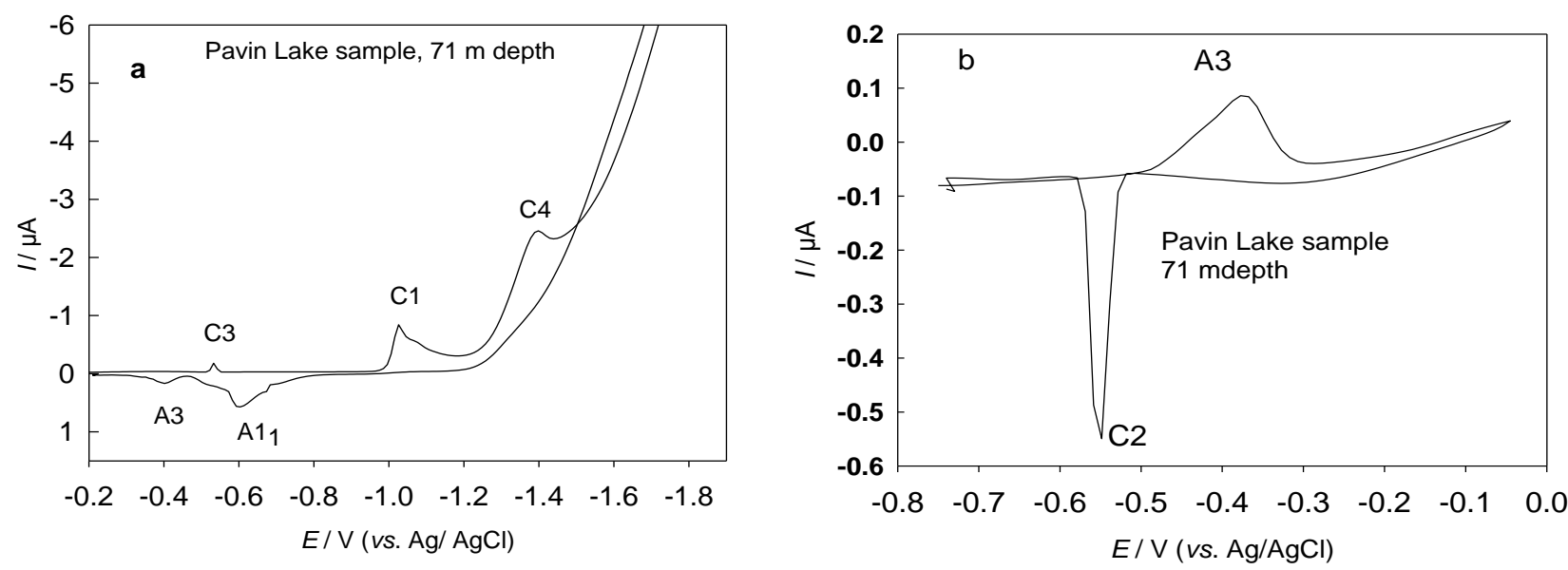

Figure 4. Typical voltammetric curves of anoxic sulfide and iron rich samples taken from crater Pavin Lake, France at $71 \mathrm{~m}$ depth $\left(\mathrm{E}=-0.2 \mathrm{~V}, \mathrm{t}_{a}=0 \mathrm{~s}\right.$ for $a$, and $\mathrm{E}=-0.75 \mathrm{~V}, \mathrm{t}_{a}=30 \mathrm{~s}$ for $b$. A3 peak is a rough measure for FeS nanoparticles presence.

In order to better characterize and possibly quantify concentration of the formed MS NPs and to estimate its size ranges in water samples, additional chronoamperometric measurements were employed for characterization of FeS NPs recently. It was shown that recorded chronoamperemetric signals are carrying FeS NPs size, possibly charge and concentration information [32]. Similar approach was adopted here for PbS NPs characterization (Figure 5).

The PbS is chosen as one of the models because its redox chemistry is relative simple and not governed by multiple relevant redox states in comparison with $\mathrm{Cu}$ and Fe and in several anoxic 
samples occasionally voltammetric peak at $-1.2 \mathrm{~V}$ similar as shown in Figure 2, was detected. In accordance with our previous studies $[11,17]$ this peak is attributed to the reduction of the $\mathrm{PbS}$ NPs according to reaction (8):

$$
\mathrm{PbS}+2 \mathrm{e}^{-} \rightarrow \mathrm{Pb}(\mathrm{Hg})+\mathrm{HS}
$$

Consequently, the chronoamperometric measurements were started in the area of the C5 peak potential (Figure 2) and the highest frequency of spike like signals were detected at $-1.5 \mathrm{~V}$. The recorded chronoamperometric curves at $-1.5 \mathrm{~V}$ were characterized by the sharp reduction current transients with duration lasting from $100 \mathrm{~ms}$ and higher and peak heights in the range of $10^{-10}$ to $10^{-8} \mathrm{~A}$. It is assumed that each spike represents a reduction of the PbS NPs at the Hg surface during collision according to reaction 8 .

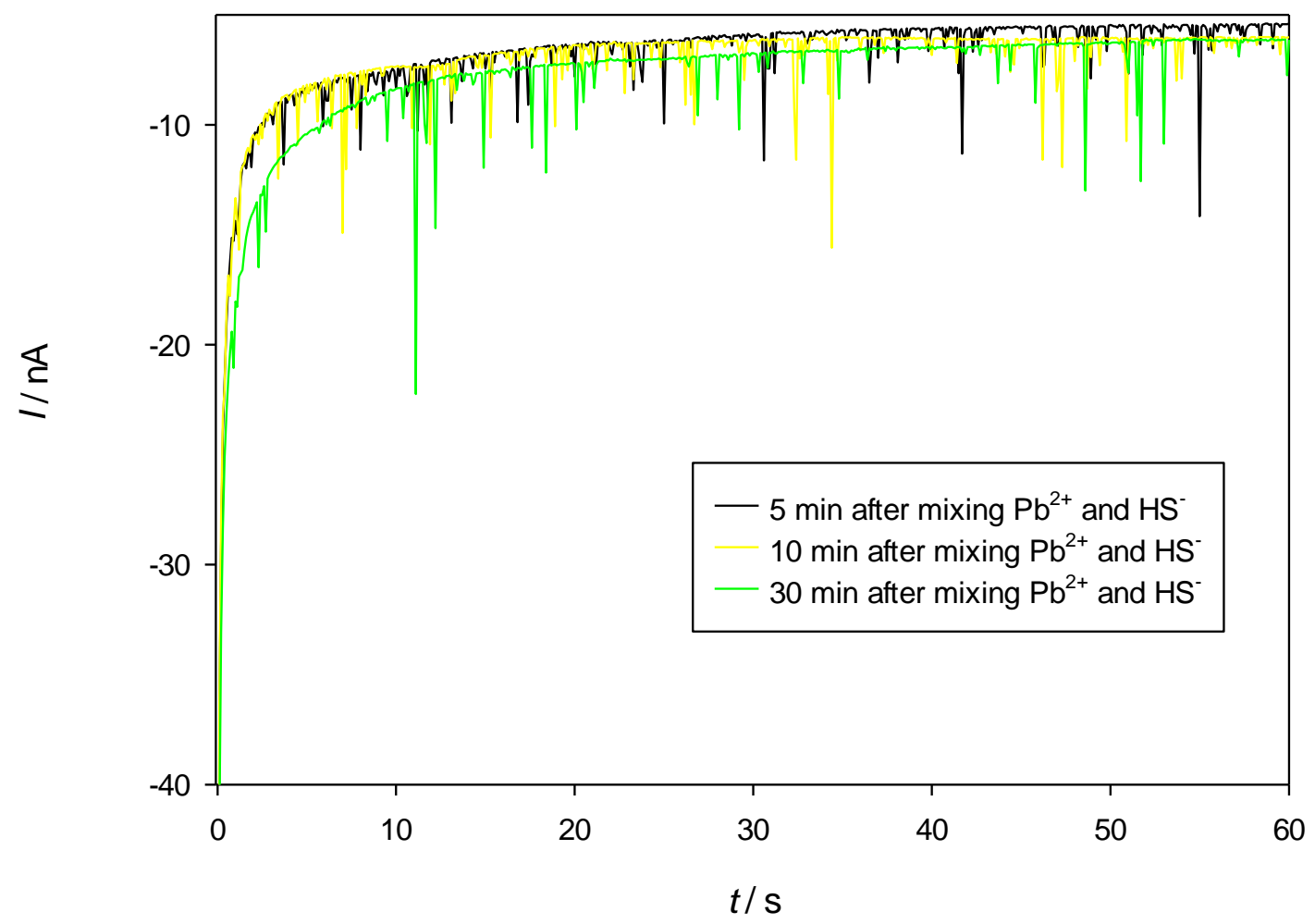

Figure 5. Chronoamperograms for $5 \times 10^{-5} \mathrm{M} \mathrm{Pb}^{2+}$ and $\mathrm{HS}^{-}$in $0.11 \mathrm{M} \mathrm{NaCl}^{\circ} 0.03 \mathrm{M} \mathrm{NaHCO}_{3}$ recorded at $-1.5 \mathrm{~V}$ (vs. Ag/AgCl) $5 \mathrm{~min}$ (black curve), $10 \mathrm{~min}$ (yellow curve) and $30 \mathrm{~min}$ (green curve) after mixing of $\mathrm{Pb}^{2+}$ and $\mathrm{HS}$.

Recorded spikes appear to be sensitive on concentration of the PbS NPs in the solution, $\mathrm{pH}$ changes, ionic composition and ageing time, similarly as obtained with FeS NPs. Please be aware that in the case of FeS NPs, recorded spike like signals were caused by catalytic processes that occurred on the FeS NPs surface during collision with the $\mathrm{Hg}$ electrode [32]. In Figure 5, it is evident decrease in the signals frequency and increase of signals charge with ageing time of the $\mathrm{PbS}$ suspension. In the given time, size of the formed PbS NPs, monitored by dynamic light scattering measurements were changed from 140 to $480 \mathrm{~nm}$ according to number size distribution. All above mentioned parameters (concentration, $\mathrm{pH}$, suspension composition, and ageing time) highly influence physico-chemical properties of the formed NPs, indicating a great potential of the chronoamperometric measurements for the characterization, quantification and sizing of all chalcogenides and other NPs which behave similarly at the $\mathrm{Hg}$ surface. 


\section{Conclusion}

In this work it is clearly shown how electrochemistry by choosing appropriate methodology and experimental conditions can be successfully used for characterization, speciation and deterimantion of different dissolved and colloidal sulfur species in natural waters including rain precipitation and aerosols. Further, it appears that today, in the time of growing nanotechnology and production of different NPs and nanomaterials, electroanalytical methods due to its relative simplicity and prompt response, low cost and relatively high sensitivity and selectivity, might be a good alternative analytical tools for characterization and possibly quantification of different NPs in natural waters. This work is still challenging for the future.

Acknowledgements: This work is supported by the Ministry of Science and Technology of the Republic of Croatia Projects: 'Nature of organic matter, interaction with traces and surfaces in environment' (number 098-0982934-2717) and 'Nanoparticles in aqueous environment: electrochemical, nanogravimetric,STM and AFM studies', a Unity through Knowledge Fund, UKF project.

\section{References}

[1] K. Rajeshwar, J. G. Ibanez, Environmental Electrochemistry, Academic Press, San Diego, CA, 1997.

[2] J. Buffle, M-L Tercier-Waeber, Trends in Anal Chem. 24 (2005) 172-191

[3] G.W., Luther, A.E., Giblin, R. Varsolona, Limnol. Oceanogr. 30 (4) (1985) 727-736.

[4] J.Buffle, O. Zali, R. De Vitre, Sci. Tot. Environ. 46(1-2)( 1987) 41-59.

[5] N. Batina, I. Ciglenečki, B. Ćosović, Anal. Chim. Acta 267 (1992) 157-164.

[6] I. Ciglenecki, Z. Kodba, B. Ćosović, Mar. Chem. 53 (1996) 101-110.

[7] I. Ciglenečki, B. Ćosović, Electroanalysis 9(10) (1997) 1-7.

[8] W. Davison, J. Buffle, R. De Vitre, Anal. Chim. Acta 77 (1998) 193-203.

[9] I. Ciglenečki, B. Ćosović, Mar. Chem. 52 (1996) 87-97.

[10] I. Ciglenečki, D., Krznarić, G.R., Helz, Environ.Sci.Technol. 39(19) (2005) 7492-7498.

[11] E. Bura-Nakić, D. Krznarić, D. Jurašin, G. R. Helz, I. Ciglenečki, Anal. Chim. Acta 594 (2007) 44-51.

[12] E. Bura-Nakić, E. Viollier, D. Jezequel, I. Ciglenečki, Chem. Geol. 266 (2009) 320-326.

[13] E. Bura-Nakić, G.R. Helz, B.Ćosović, I.Ciglenečki, Geochim.Cosmochim.Acta 73 (2009) 37383751.

[14] E. Bura-Nakic,D. Krznarić, G.R. Helz, I. Ciglenečki, Electroanalysis 23 (2011) 1376-1382.

[15] I. Ciglenečki, E. Bura-Nakić, M. Marguš, J. Solid State Electrochem. 16(6) (2012) 2041-2046.

[16] E. Bura-Nakić, E. Viollier, I. Ciglenečki, Environ. Sci. Technol. 43 (2013) 741-749.

[17] I. Milanović, D. Krznarić, E. Bura-Nakić, I. Ciglenečki, Environ. Chem. 11(2014) 167-172.

[18] B. Ćosović, V. Vojvodić, Limnol. Oceanogr. 27 (1982) 361-369

[19] B. Ćosović, V. Vojvodić, Electroanalysis 10 (1998) 429-434.

[20] B.Ćosović, Z.Kozarac, S.Frka, V.Vojvodić, Electroanalysis, 22 (17-18) (2010) 1994-2000.

[21] M.-L. Tercier, J. Buffle, A. Zirino, R.R. De Vitre, Anal. Chim. Acta 237 (1990) 429-437

[22] E. P.Acherberg, C. Braungardt, Anal.Chim.Acta 40 (1-3) (1999) 381-397.

[23] M. Taillefert, M., G.W. Luther III, D.B. Nuzzio, Elecroanalysis 12 (2000) 401-412.

[24] I. Pižeta, G. Billon, J-C. Fisher, M. Wartel, Electroanalysis 15 (17) (2003) 1389-1396.

[25] G.W. Luther, B. Glazer, S. Ma, R. Trouwborst, B.R. Shultz, G. Druschel, C. Kraiya, Aquatic. Geochem. 9 (2003) 87-111.

[26] C.B.Braungardt, E. Achterberg, B. Axelsson, J.Buffle, F.Graziottin, K.A. Howell , S. Illuminati, G. Scarponi, A.D.Tappin, M.-L. Tercier-Waeber, D.Turner D. Mar. Chem. 114 (2009) 47-55

[27] A.D. Clegg, N.V. Rees, C.E. Banks, R.G. Compton, Chem. Phys. Chem. 7 (2006) 807-811. 
[28] J. Cutress, N.V. Rees, Y. Zhou, R.G. Compton, J. Phys. Chem. Lett. 514 (2011) 58-61.

[29] Y. Zhou, N.V. Rees, R.G. Compton, J. Phys. Chem. Lett. 511 (2011) 183-186.

[30] Y. Zhou, N.V. Rees, R.G. Compton, Angew. Chem. Int. Ed. 50 (2011) 4219-4221

[31] Y. Zhou, N.V. Rees, J. Pillay, R. Tshikhudo, S. Vilakazi, R.G. Compton, Chem. Commun. 48 (2012) 224-226.

[32] E. Bura-Nakić, M. Marguš, I. Milanović, D. Jurašin, I. Ciglenečki, Environ.Chem. 11 (2014) 187-196.

[33] S. Kariuki, M.J. Morra, K.J.Umiker, I.F. Cheng, Anal. Chim. Acta 442 (2) (2001) 277-285.

[34] K.J. Umiker, MJ. Morra, I.F. Cheng, Microchem. J. 73 (2002) 287-297.

[35] K. Winkler, T. Krogulec, J. Electroanal. Chem. 386 (1995) 127-134.

(C) 2014 by the authors; licensee IAPC, Zagreb, Croatia. This article is an open-access article distributed under the terms and conditions of the Creative Commons Attribution license (http://creativecommons.org/licenses/by/4.0/) (cc)) Br 